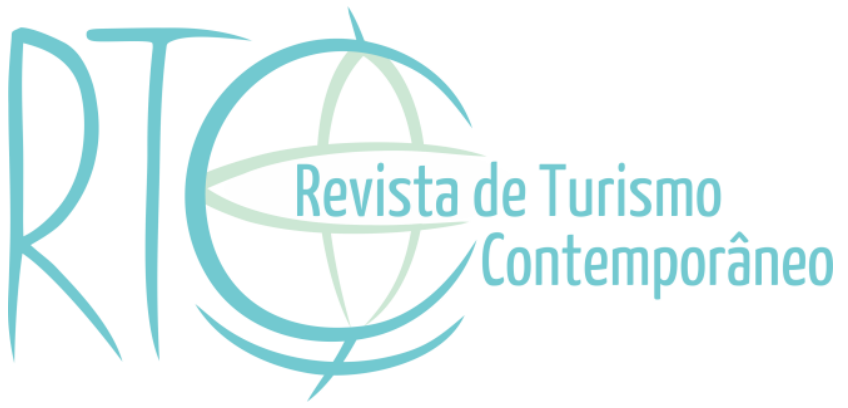

\title{
Revisitando conceitos sobre políticas públicas e gestão do turismo em cidades
}

\author{
Revisiting concepts on public policies and \\ tourism management in cities
}

Saulo Ribeiro dos Santos

Professor Adjunto do Departamento de Turismo e Hotelaria da Universidade Federal do Maranhão-UFMA, São Luiz /MA, Brasil.

E-mail: saulosantosma@uol.com.br

Artigo recebido em: 26-02-2016

Artigo aprovado em: 14-12-2016 


\section{RESUMO}

As políticas públicas são estruturas criadas pelo setor público com o objetivo de atender necessidades, expectativas e interesses da sociedade. A discussão das políticas está no processo da formulação e aplicação, e as cidades por terem se tornado locais de desenvolvimento da prática turística em decorrência do planejamento urbano constitui-se como uma tendência de análise sobre as abordagens de temática essencial do trabalho. Tratase de um artigo de revisão bibliográfica sobre política pública de turismo e gestão de cidades e sua relação, apontando aspectos estudados sob a ótica de diversos autores, direcionando meios quanto a lacunas existentes no âmbito teórico. $\mathrm{O}$ aporte metodológico fundamenta-se em uma extensa revisão bibliográfica, documental e webresearch, com dados secundários, com abordagem qualitativa, caracterizando-se como pesquisa exploratória e descritiva, respaldado por autores como Aretche (2010), Butler (2008), Chang e Huang (2004), Mullins (1991), Souza (2004) e Yázigi (2009) que contribuem para uma análise crítica sobre a temática. Aponta-se que a execução de políticas públicas urbanas, contribuem como um elemento dinamizador de desenvolvimento, pois, a cidade passa a oferecer produtos pensados tanto para autóctones como visitantes, contribuindo para a atividade turística

Palavras-chave: Políticas públicas. Planejamento turístico. Turismo urbano.

\section{ABSTRACT}

Public policies are structures created by the public sector in order to meet needs, expectations and interests of society. The discussion of policies is in the design and implementation process, and the cities for making up the tourist practice development sites due to urban planning was established as a trend analysis on key thematic approaches work. This is a literature review on public policy on tourism and city management and its relationship, pointing aspects studied from the perspective of several authors, directing means and the gaps that have been neglected. The methodological approach is based on an extensive literature review, document and webresearch with secondary data with a qualitative approach, characterized as exploratory and descriptive research, supported by authors such as Aretche (2010), Butler (2008), Chang and Huang (2004), Mullins (1991), Souza (2004) and Yázigi (2009) that contribute to a critical analysis of the subject. It points out that the implementation of public policy in large cities tourism contributes as a catalyst for development element, because the city will offer products designed for both native and visitors.

Keywords: Public policies. Tourism planning. Urban tourism. 


\section{INTRODUÇÃO}

A devida compreensão do ordenamento territorial do espaço no qual se desenvolve a atividade turística é um dos problemas que vêm sendo encarados por pesquisadores (Cooper, Hall \& Trigo, 2011). Além disso, a população está cada vez mais morando nas cidades ${ }^{1}$ e adaptando-se aos espaços existentes a eles destinados (Auch, Taylor \& Acevedo, 2004). Mas para que as urbes possam desenvolver-se e atender as necessidades da sociedade e turistas é necessário à criação e implantação de políticas públicas que estejam alinhadas ao ordenamento do território (Chang \& Huang, 2004).

Neste aspecto, diversas políticas públicas (legislação e instrumentos de participação) destinadas às cidades foram elaboradas com este objetivo como o Estatuto da Cidade (Lei 10.257/2001) que contribuem para a criação de estruturas urbanísticas básicas (Lefebvre, 2011; Santos, 2015). Enquanto que as políticas públicas de turismo estão "intimamente relacionadas com os valores culturais e ideológicos, com o ambiente político e com as estruturas institucionais, e refletem as tendências e preocupações do momento de sua elaboração" (Solha, 2004, p. 11).

Por outro lado, o turismo como um setor econômico que consome produto (Butler, 2008), utiliza os espaços das urbes com fins de lazer. "O urbano realmente não é o único tipo de território onde o turismo acontece, mas certamente é um dos lugares mais importantes considerando o fato de que, é o lugar por excelência do encontro social e cultural" (Roscoche, 2013, p. 815).

A cidade como objeto de estudo é descrita como um ambiente artificial construído e inventado pelo ser humano com o objetivo de viver em sociedade, pois além de urbano, é também cultural. $\mathrm{O}$ crescimento da população mundial promoveu o deslocamento das pessoas das áreas rurais para regiões urbanizadas (Auch, Taylor \& Acevedo, 2004), fazendo com que as cidades passassem a se tornar o equilíbrio da dimensão humana, e também as receptoras do fluxo comercial e das mudanças de produção promovidas pela Revolução Industrial. Essa

${ }^{1}$ Cerca de $54 \%$ da população do mundo é urbana, conforme o relatório publicado, intitulado "Perspectivas da Urbanização Mundial” da Organização das Nações Unidas (ONU, 2014), onde a maioria nasce, cresce e vive, reconhecendo este espaço artificial como seu local. 
aceleração tem criado patamares expressivos de urbanização com a criação de megalópoles ${ }^{2}$ (Chang \& Huang, 2004; Hayllar, Edwards, Griffin \& Aldrigui, 2011). Assim, as políticas públicas contribuem para a criação de locais públicos que tornam-se espaços consumidos pela atividade turística como no caso da paisagem urbana (Ashworth \& Page 2011; Beni, 2006). Estudos sobre a gestão do turismo urbano (Ashworth \& Page,2011) estão condicionados a inúmeros subtemas como marketing, impactos, sustentabilidade, segmentação, teoria social, transporte, infraestrutura, satisfação, entre outros, que contribuem para a definição da complexidade do fenômeno. Chang e Huang (2004) esclarecem que a globalização interfere diretamente nos destinos turísticos, principalmente no que tange a utilização deequipamentos urbanos como opção de produto turístico, como o caso de Curitiba (Brasil), Dubai (Emirados Árabes), Hong Kong (China), Johanesburgo (África do Sul), Londres (Inglaterra), Nova York (Estados Unidos), Sydney (Austrália), entre outras (Hayllar et al., 2011; López Palomeque, 2009; Nam \& Pardo, 2011).

Assim, objetiva-se promover uma discussão teórica sobre políticas públicas e sua relação com a gestão do turismo urbano.

A escolha adequada do desenho metodológico adotado nesta pesquisa foi o desk research, para a consecução de um estudo de qualidade. A pesquisa é considerada exploratória e descritiva, pois proporciona maior familiaridade com o objeto de estudo e aprimoramento das ideias. Realizou-se levantamento de dados bibliográficos e documentais, nos quais os conhecimentos produzidos visam ampliar estratégias que proporcionem compreender a reflexão sobre a temática (Cooper \&Schindler, 2003; Gil, 2006). Quanto ao tipo de análise estratégica utilizou-se a qualitativa que segundo Minayo e Sanches (1993) é empregada para a compreensão dos fenômenos e contribui para a observação de valores, hábitos, atitudes, crenças, representações e opiniões.

Este tipo de estudo visa proporcionar um maior "conhecimento para o pesquisador acerca do assunto, a fim de que esse possa formular problemas mais precisos ou criar hipóteses que possam ser pesquisadas por estudos posteriores” (Gil, 2006, p. 43).

Com este artigo, pretende-se contribuir de forma significativa com uma reflexão quanto à relação entre política pública e gestão do turismo urbano, sob a ótica de autores e

2 ،

2 "Rede urbana muito densa, conectando de forma bastante complexa diversas entidades urbanas (distritos, cidades, aglomerações urbanas e metrópoles), constituindo uma ampla conurbação funcional, não necessariamente uma conurbação física - ainda que esta seja frequente em vastas porções dos territórios megalopolitanos" (Queiroga; Benfatti, 2007, p.42). 
pesquisadores do turismo, na sua relação direta como matéria recente do campo de pesquisas acadêmicas sociais (Mazaro, 2011).

\section{POLÍTICAS PÚBLICAS E GESTÃO DO TURISMO URBANO}

Aguiar e Dias (2002) alertam que o turismo assume relevante papel na atualidade, em que as pessoas buscam cada vez mais fugir do estresse diário por meio de viagens, conhecendo novas localidades e culturas, gerando emprego e renda. Atualmente, é um dos setores da economia (Sanz-Ibanez \& Anton, 2014) que mais cresce no mundo, representando importante aliado nas contas internas de muitos países ${ }^{3}$.

Somente depois que a atividade começou a ter tal representatividade econômica, como afirma Solha (2004, p. 09), onde "no turismo as preocupações em se estabelecer políticas para o setor só aparecem quando este adquire importância econômica", é que se começou a pensar no seu planejamento /estruturação, formulação/implantação como ferramenta de difusão de culturas, de criação de negócios e recentemente no apoio a preservação do meio ambiente (Mtur, 2013).

Entretanto, o turismo não é apenas uma atividade geradora de rendas, sendo definido por Dias (2003, p.45) como:

$\mathrm{O}$ conjunto de atividades que as pessoas realizam durante suas viagens e estadas em lugares diferentes ao de seu entorno habitual, por um período de tempo consecutivo inferior a um ano, com o objetivo de lazer, negócios ou outros motivos, não relacionados com uma atividade remunerada no lugar visitado.

Portanto, compreender o turismo em sua natureza complexa e dinâmica da experiência contemporânea está conexo ao conceito de sistema de turismo, que é "uma mistura ou uma combinação inter-relacionada de coisas ou elementos que formam um todo" (Cooper, Hall \& Trigo, 2011, p. 5). E o mais importante para se compreender tal aspecto é que ele está relacionado ao conjunto de consumo, produção e experiências (Pine \& Gilmore, 2011) geradas num ambiente gerador de fluxo de visitantes de uma localidade para outra,

\footnotetext{
${ }^{3}$ Dados a Exceltur apontam que em 2015, o turismo foi o setor da economia que mais cresceu na Espanha, com um acréscimo de 3,7\% em comparação ao ano anterior, e gerou 124 milhões de euros.
} 
conectando o destino emissor ao receptor.

Esta movimentação de pessoas é perceptível principalmente em grandes centros urbanos do mundo (Roscoche, 2013), pois, o turismo na cidade ${ }^{4}$ desenvolve-se mediante uma estrutura conceitual (Figura 1) que engloba toda a funcionalidade de uma área turística funcional na urbe, desde as relações com a cidade, experiências e comportamentos, impactos, políticas e resultados. Esta dinâmica sistêmica apresentada esclarece a funcionalidade da atividade num destino urbano, de forma estruturada para que ocorra possíveis benefícios associados ao desenvolvimento do turismo na cidade (Ritchie \& Dickson, 2006).

Analisa-se na figura abaixo, a complexidade de um destino urbano, onde as políticas e planejamento devem estar diretamente conectadas às experiência e comportamento da área funcional, enfatizando as qualidades existentes, para que promova resultados positivos, quanto aos impactos causados pelo turismo, nos âmbitos ambiental, econômico e social, além disso, tendo uma relação favorável da cidade com a atividade turística, contribuindo diretamente para o setor.

Figura 1 - Áreas funcionais turísticas urbanas: uma estrutura conceitual

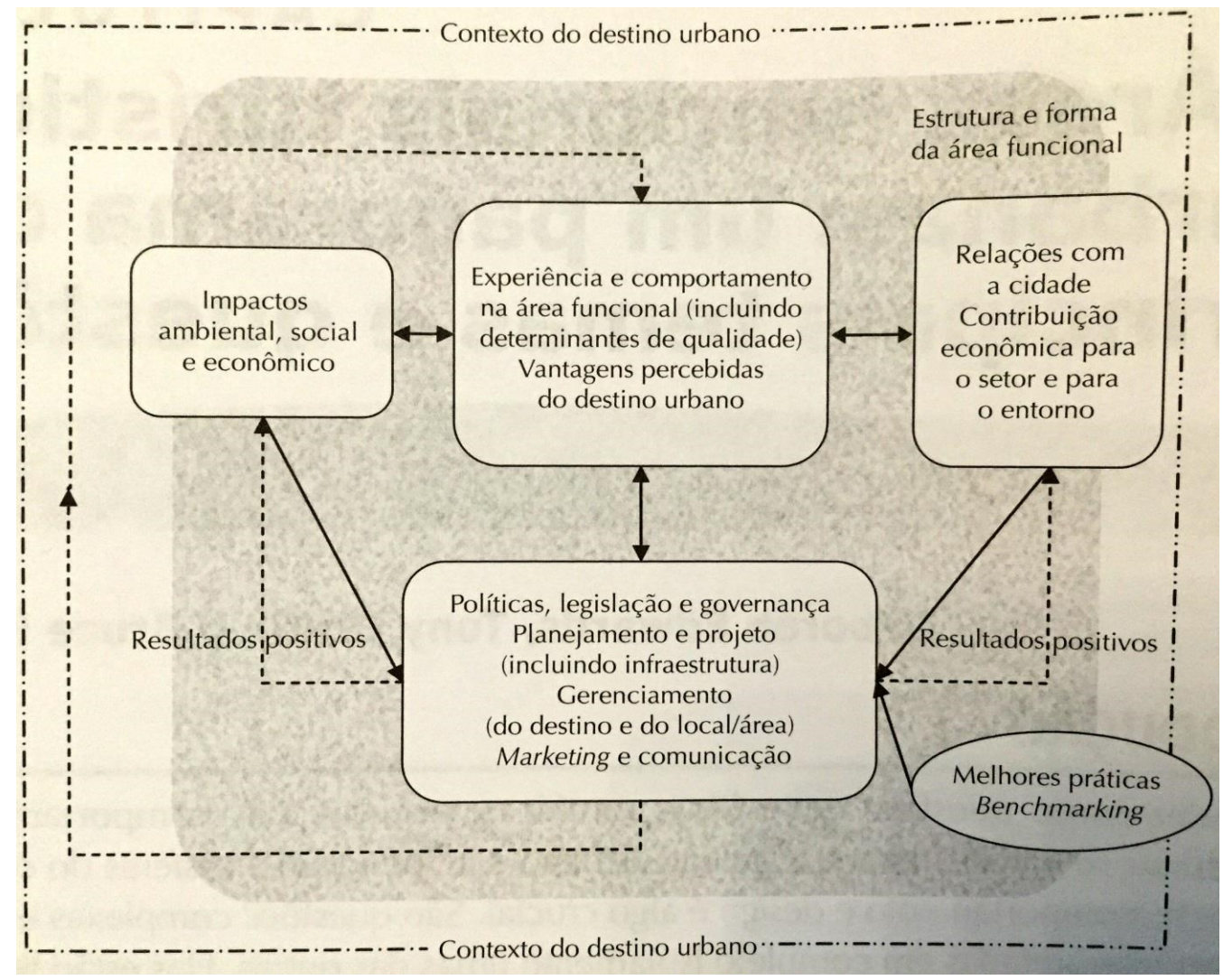

Fonte: Hayllar et al. (2011, p. 42)

${ }^{4}$ A cidade é o "produto da interaçáo entre agentes sociais, pertencentes à iniciativa privada, ao poder público e a sociedade civil" (Ruiz; Gândara, 2013, p. 261). 
O turismo nas cidades representa uma forma extraordinária de uso da urbanização como atrativo, pois "são organizadas não para a produção, como foram as [...] industriais, mas com o consumo de bens, serviços e paisagens" (Luchiari, 1998, p. 108). Adicionando, argumenta-se que o turismo urbano progredirá academicamente quando estiver alinhado aos estudos das ciências sociais, o que levará o turismo a integração dos debates acadêmicos da área (Hall, 2011; Rullán, 2011).

Enquanto isso, os estudos de Mullins (1991) apontam características do lazer nos centros urbanos na Era Pós-Moderna, pois o turismo não acontece somente neste território, mas é um dos locais mais importantes da atividade, por excelência, pois, justifica-se como social e cultural, além de possuir função varejista e de entretenimento (Pearce, 2001; Roscoche, 2013)

\begin{abstract}
Os espaços urbanos são lugares nos quais as pessoas gostam de andar independente de ter um objetivo ou não -, é a forma física (definida por coisas como prédios individuais, fachadas e arquitetura) que determina, dentro da área funcional turística, os indicadores que auxiliam o visitante a situa sua experiência. Disposta sobre esta estrutura física, uma área turística é capaz de desempenhar funções bem definidas que atendem às demandas pessoais e físicas dos visitantes (Hayllar, et al, 2011, p. 43).
\end{abstract}

Além disso, a cidade tornou-se um dos principais destinos explorados pela atividade turística (Yázigi, 2003), pois o fascínio pelas urbes descrito por Karski (1990) argumenta que estas possuem atributos e oportunidades quanto à localização, escala e experiências diversas conforme argumentam Pine e Gilmore (2011).

As cidades recebem um considerável volume de tráfego, gerado pelas várias funções que exercem, sejam elas administrativas, comerciais e/ou industriais, que atraem grande número de grupos de visitantes. Muitos centros urbanos possuem funções varejistas e de entretenimento e refletem funções contemporâneas [...] O novo e o velho interagem num movimento constante, pois nesses centros existe a concentração de edifícios e monumentos históricos coexistindo com inúmeras edificações e tecnologias pós-modernas (Roscoche, 2013, p. 815). 
O turismo urbano está relacionado a processos sociais de mudança e decisão política, que orientam para mudanças que afetam a sociedade e a cidade. Tyler, Guerrier e Robertson (2001, p. 309), acreditam que o turismo nas cidades "deve transcender à simples questão da oferta e da procura e inserir-se como um mecanismo de gestão e modificação das cidades e de suas funções, fazendo com que promova uma resposta social e política para a sociedade pósmoderna".

Estudos sobre o turismo urbano na academia são recentes, datados da década de 80 (Ashworth \& Page, 2011) e pouco estudados em comparação ao meio natural, enquanto que o interesse pelo meio urbano e turismo estão relacionados principalmente à conservação dos centros urbanos e centros históricos ou sobre temáticas de oferta e demanda (Pearce, 2001; 2003; Santos, 2015; Tyler, Guerrier \& Robertson, 2001).

As pesquisas sobre turismo urbano estão direcionadas principalmente a planejamento, economia, marketing, organização e desenvolvimento (Yázigi, 2009), sendo possível incluir e utilizar outras temáticas sobre o ordenamento territorial e espacial numa variedade de contextos (L.González, P. González \& Escuredo, 2012), pois a atividade turística não é isolada conforme destacada na figura 1, pois o fenômeno turístico no meio urbano "se deu em razão de sua complexidade, representando assim um grande desafio para muitos pesquisadores no momento de registrar movimentos e observar comportamentos" (Roscoche, 2013, p. 817).

Pearce $(2001$; 2003) e Yázigi (2009) esclarecem que o turismo urbano deriva de um estudo complexo sobre a organização do território, pois, "a complexidade, fragmentação e falta de coerência implica um esquema de estudo claro e analítico que proporcione uma perspectiva mais sistemática sobre os temas próprios do turismo urbano" (Pearce, 2001, p. 342). Portanto, há uma necessidade de análise integrada sobre a conexão entre turismo e cidades exposto nos estudos de Santos (2015).

Neste aspecto, compreender as políticas públicas direcionadas as cidades é fundamental, pois, estas de certa forma, interferem no planejamento turístico (Ruiz \& Gândara,2013), pois, como citado anteriormente, algumas cidades do mundo, possuem atrativos oriundos de políticas públicas e planejamento urbano, que foram desenvolvidos para a comunidade, mas que o turista utiliza como espaço de visitação (Tyler, Guerrier \& Robertson, 2001). 
Knafou (2001, p. 68) completa afirmando que:

[...] a cidade turística é uma aglomeração urbana onde o turismo é considerado uma atividade importante para a economia local, e pode se apresentar em termos espaciais de duas formas: uma delas é multiplicidade de sítios integrados ao tecido urbano onde a apropriação por parte do turismo de algumas zonas de uso coletivo como áreas verdes e as áreas de lazer das cidades; a outra forma é a estação turística que se define pela primazia do turismo em relação às demais atividades, isto é, o turismo produziu aquele lugar e constitui a atividade econômica predominante.

Fica evidente a relação do turismo com as cidades, pois a estrutura urbana é fundamental para o desenvolvimento da atividade na urbe. Yázigi (2003) acrescenta que dentre os segmentos do turismo, o urbano é o mais importante, pois, por excelência é local de encontro cultural e social, além de ser um ambiente digno que o turista procura. Por outro lado, neste território são ofertados empreendimentos que promovem garantias e sensações, quanto a uma experiência de qualidade.

Mas para tanto, a ciência política (Souza, 2004) que compreende a análise histórica de várias civilizações, determinando o ordenamento dos poderes e regulando a organização social, favorece na compreensão do processo das funções do espaço urbano e turístico. Bonavides (2006) complementa que é a disciplina que interpreta os acontecimentos, as ideias e as instituições, tanto doutrinariamente quanto no seu sentido prático.

O termo política não é de fácil definição e, com o passar dos anos, várias foram as tentativas nesse sentido. De acordo com Santos (2008), seu surgimento remonta ao período da Grécia Clássica, por meio de Aristóteles ${ }^{5}$, e tem origem no vocábulo grego "politike", referindo-se a polis ${ }^{6}$, sendo entendido, portanto, como o pleno exercício da cidadania, em uma sociedade organizada, formada pelos cidadãos.

Não existe uma definição melhor ou única sobre o que seja política pública, mas na visão de Souza (2004, p. 25) ela assume,

Uma visão holística do tema, uma perspectiva de que o todo é mais importante do que a soma das partes e que indivíduos, instituições,

5

Nascido em 384 a.C. na colônia grega de Estágira, Aristóteles baseou suas principais contribuições filosóficas nas ideias sobre a humanidade e como estas têm influência na educação e no pensamento ocidental contemporâneo. É considerado o criador do pensamento lógico e também influenciou na teologia medieval da cristandade (Stokes, 2012).

As polis eram cidades estado da Grégia antiga, ou seja, eram independentes, com liberdade econômica e política (Lobato, 2001). 
interações, ideologia e interesses contam, mesmo que existam diferenças sobre a importância relativa destes fatores [...] a política pública em geral e a política social em particular são campos multidisciplinares, e seu foco está nas explicações sobre a natureza da política pública e seus processos. Por isso, uma teoria geral da política pública implica a busca de sintetizar teorias construídas no campo da sociologia, da ciência política e da economia. As políticas públicas repercutem na economia e nas sociedades, daí por que qualquer teoria da política pública precisa também explicar as inter-relações entre Estado, política, economia e sociedade.

O crescimento e interesse comum na área tem contribuído para os avanços teóricos no campo do conhecimento, pois, a política pode ser interpretada como forma de gerenciamento de diversos interesses, em prol dos mesmos objetivos, ou seja, "colocar o governo em ação e/ou propor mudanças no rumo ou curso das ações" (Souza, 2004, p.26).

E de fato as políticas urbanas interferem no processo do planejamento urbano, com o objetivo de reordenar o espaço urbano moderno, integrando ações que permitam o desenvolvimento da atividade turística de forma a atrair e manter o destino turístico competitivo. Ashworth e Page (2010) afirmam que o turismo utiliza as instalações localizadas em áreas urbanas, e que de alguma forma o aspecto "urbancity" é a uma das principais motivações do turista (Yázigi, 2003; 2009).

As cidades transformaram-se mediante políticas públicas (Arretche, 2010; Mullins, 1991; Souza, 2004) para atender as exigências do mercado turístico, gerando um novo modelo de urbanização que Mullins (1991) descreve como uma urbanização baseada na venda e no consumo do lazer. Algumas cidades redefinem suas atividades econômicas em prol do desenvolvimento turístico, produzindo espaços turistificados, como Luchiari (2000) define que estas cidades possuem uma extraordinária forma de urbanização, pois foram direcionadas para o consumo de bens, paisagens e serviços. Chang e Huang (2004) e Pearce (2001) esclarecem que a urbanização está direcionada a criação de infraestrutura para o turismo, ou seja, políticas públicas que atendam às necessidades de cada localidade e suprindo as deficiências existentes, principalmente em sua fase de implantação. Conforme Lobato (2001) deve ser considerado como base para evidência dos caminhos a serem utilizados para satisfação do bem comum.

Para Lobato (2001, p.87), existem três pontos de vista a partir dos quais se pode conceituar a política: "o da participação do homem na sociedade, o referente ao planejamento e o da atuação dos poderes públicos". Ou "a formulação de políticas públicas constitui-se no estágio em que os governos democráticos traduzem seus propósitos e plataformas eleitorais em programas e ações que produzirão resultados ou mudanças no mundo real" (Souza, 2004, 
p. 26).

Enquanto participação do homem na sociedade torna-se um instrumento que permite o desenvolvimento organizado da vida em comunidade. Quanto ao planejamento, compõe o conjunto de orientações que facilitam o processo de tomada de decisões por parte do planejador, indicando-lhes parâmetros e direções para o alcance dos objetivos estabelecidos. Do ponto de vista da atuação dos poderes públicos, é entendida como a ação dos mesmos em favor da sociedade (Faria, 2003).

Para que seus benefícios tenham foco na sociedade, é preciso que o Estado seja o seu agente regulador, instituindo políticas públicas cujos objetivos visem ao bem-estar social (Arretche, 2010).

\begin{abstract}
As políticas públicas têm como função histórica apresentar à sociedade ações para minimizar ou solucionar problemas que, porventura, aflijam ou afetem a população, com o objetivo de contribuir para com o amadurecimento da cidadania, alcançando assim, a participação da população na construção da nação (Vieira, 2008, p.16).
\end{abstract}

Por meio de um conjunto de ações executadas em âmbito estatal visando à coletividade, a política pública visa suprir as necessidades de dada sociedade (Dias, 2003). É importante, porém, ressaltar que, apesar da expressiva participação da população, seu estabelecimento é ação exclusiva do Estado, o qual deve definir, solidariamente, as metas e objetivos a serem alcançados (Arretche, 2010).

Entretanto, o termo "políticas públicas" vem sendo entendido como um meio de intervenção dos mandatários, ou seja, daqueles que exercem o poder sobre a comunidade, não estabelecendo a promoção do bem-estar da sociedade a partir da satisfação comum.

Para que haja mudanças nessa concepção, torna-se necessária a existência de atuação conjunta dos órgãos públicos com a sociedade civil organizada e com a iniciativa privada. Dias (2003, p.123) enfatiza que "nos vários níveis que possa ocorrer a implementação de uma política pública, diversos agentes devem ser considerados."

Complementando, Beni (2006, p.79) conclui que "apesar da presença marcante da iniciativa privada na coadjuvação do Estado nesse exercício das funções coletivas, este detém não só a diretriz”. Dessa forma, o autor explicita a importância da aliança entre os vários 
níveis da sociedade (Estado, iniciativa privada e comunidade local), cabendo, porém, ao Estado a definição e a gerência das ações e resultados alcançados pelas políticas públicas.

Bonavides (2006) comenta que a sociedade atual vem sofrendo alterações nos seus modos de vida, resultantes do advento da tecnologia e da expansão das comunicações, que servem para estabelecer formas de interconexões com o planeta, bem como para alterar intimamente o cotidiano dos indivíduos e dos grupos sociais.

Para que ocorra o crescimento da atividade turística, a atuação do poder público é essencial como responsável pelo seu direcionamento, garantindo os interesses coletivos e sobrepondo-os aos de um pequeno grupo ou de um indivíduo (Castrogiovanni, 2013; Santos, 2015).

As políticas de turismo estão intimamente relacionadas com os valores culturais e ideológicos, com o ambiente político e com as estruturas institucionais, e refletem as tendências e preocupações do momento em sua elaboração. Portanto, a política de turismo deve funcionar tanto no estímulo e no controle direto do desenvolvimento do turismo, como também preocupar-se com a proteção dos interesses da sociedade Solha, 2004, p. $11 ; 13)$

Devido ao expressivo crescimento do setor turístico, a iniciativa privada e o poder público passaram a dar mais ênfase à atividade, cabendo ao Estado a formulação e a aplicação de políticas a partir de um processo de planejamento pré-estabelecido.

O turismo é um produto multifacetado, pois inclui acomodação, transportes, restaurantes, facilidades de compras, atrações turísticas, apoio de infraestrutura pública e o modo de vida da comunidade hospedeira, e só pode ser bem sucedido se existir uma sintonia entre esses setores que proporcionem satisfação ao cliente - o turista (Theobald, 2002, p.19).

Confirma-se, então, a necessidade de implantação, por parte do Estado, de políticas públicas de turismo eficazes, pois essa é uma das poucas atividades econômicas capazes de englobar a maioria das potencialidades existentes em uma localidade (Plaza, 2006).

Ashworth e Page (2011) esclarecem que a gestão do turismo nas cidades é um aspecto que incorpora o funcionamento da cidade, que de certa forma é complexo (Solha, 2004), mesclando gestão e políticas urbanas de forma ampla (Castrogiovanni, 2013, Yázigi, 2003, 2009). Embora o turismo desempenhe papel fundamental nas cidades, como um instrumento de política, é assim, sem dúvida que o planejamento do turismo urbano envolve uma multiplicidade de organismos públicos e privados, que combinam instrumentos como o Plano 
Diretor, por exemplo (Ruiz \& Gândara, 2013).

Desenvolver políticas públicas urbanas com viés turístico tem no seu uso, aspectos de regeneração urbana, e revitalização de equipamentos urbanos. No entanto, só consegue desenvolver potencialidades se for implantada de forma planejada, maximizando os impactos positivos e minimizando os negativos, transformando, paulatina e equilibradamente, a economia do destino, captando grandes investimentos para o local.

A política de turismo é a espinha dorsal do formular (planejamento), do pensar (plano), do fazer (projetos, programas), do executar (preservação, conservação, utilização e ressignificação dos patrimônios natural e cultural e sua sustentabilidade), do reprogramar (estratégia) e do fomentar (investimentos e vendas) o desenvolvimento turístico de um país ou de uma região e seus produtos finais (Beni, 2006, p.177).

Numa outra definição, Beni (2006) entende políticas de turismo como o conjunto de fatores condicionantes e de diretrizes básicas que expressam os caminhos para atingir os objetivos globais para as atividades turísticas de um país.

Já Carvalho (2000, p.99) define políticas públicas de turismo como:

Conjunto de decisões e ações relativas à alocação imperativa de valores, que se encontram consubstanciadas, amparadas legalmente nos programas, projetos, planos, metas e orçamentos dos poderes públicos (federal, estadual ou municipal) referentes ao turismo.

Ou seja, as políticas públicas de turismo surgem para incentivar a atividade turística de um país, integrar as pessoas que fazem parte da sociedade e os órgãos públicos e privados, com o objetivo de dinamizar o setor, gerando, assim, emprego e renda para a localidade (Santos, 2015; Solha, 2004).

No ambiente urbano (Rullán, 2011), as políticas públicas são direcionadas a constituição de um conjunto de espaços públicos como ruas, calçadas, praças, avenidas, parques, paisagens, entre outros (Auch, Taylor \& Acevedo, 2004), que possuem forte influência sobre o turismo, pois, o turista busca justamente romper com o cotidiano, e na cidade é possível conviver com novos espaços que proporcionem condições de estadia favorável. 
Para Goeldner, Ritchie e McIntosh (2002), a política de turismo, em termos mais específicos, preenche as funções de: a) definir as formas de funcionamento das operações turísticas; b) estabelecer atividades e comportamentos aceitáveis; c) fornecer orientação e direção comum aos interessados no turismo do destino; d) facilitar a conformidade em torno de objetivos e estratégias específicos para determinado destino; e) fornecer estrutura para discussões públicas e privadas sobre o papel e contribuições da atividade para a economia e para a sociedade; f) consentir que o turismo institua interfaces com outros setores da econômicos.

Enfim, é a política de turismo que define o que os envolvidos na atividade turística devem ou não fazer, e qual a melhor forma de alcançar os objetivos e metas estabelecidas previamente pelo seu planejamento.

A adoção de uma política para o turismo pode representar o papel que a atividade vai desempenhar na sociedade, assim como a relevância cultural, social e econômica para as comunidades envolvidas.

Em uma retrospectiva da história do turismo, percebe-se que foram valiosas as transformações derivadas das suas políticas nos últimos cinquenta anos, conforme apresenta Solha (2004, p.11):

1. 1950 a 1970: quando se verificava a expansão do turismo de massa, eram comuns as políticas de fomento, que tinham como principal intuito o aumento do fluxo de visitantes;

2. 1970 a 1985: as políticas começavam a focar o turismo como agente de desenvolvimento, havendo um crescente envolvimento governamental no fornecimento de infraestrutura;

3. 1985 - atual: observa-se, ao mesmo tempo, maior preocupação com as questões ambientais e um grande aumento da competitividade, estimulando um posicionamento responsável e profissional do setor, no qual o Estado diminui sua interferência e procura assumir um papel de coordenação e estruturação da atividade.

Pereira (1999) acredita que as políticas públicas de turismo surgiram na regulação do trabalho e na limitação da carga horária diária e semanal, com a implantação das férias remuneradas, com a evolução dos meios de transportes e com outras conquistas. Variando de acordo com as necessidades e com os objetivos de cada localidade, devem atuar tanto no estímulo quanto no controle do desenvolvimento turístico, além, claro, de voltar-se à proteção dos interesses da comunidade local. 
Como comentado, o ator principal na formulação de tais políticas é o Estado, cabendolhe a definição de metas e objetivos a serem alcançados, bem como a execução, a fiscalização e, até mesmo, o financiamento das ações previstas. Assim, ao mesmo tempo, torna-se o líder para a elaboração e aplicação de políticas voltadas para o desenvolvimento da atividade turística, e o fiscalizador dos resultados alcançados junto à sociedade.

Também são funções e responsabilidades do poder público, a educação e a sensibilização dos envolvidos, bem como o seu treinamento para as atividades que envolvam o turismo, que são importantes na medida em que qualificam os profissionais do setor e, assim, melhoram a qualidade da experiência turística. Dias (2003, p.45) completa, esclarecendo as áreas de atuação governamental no âmbito turístico:

a) coordenação - é um conjunto diversificado de atores que devem integrar num interesse geral em prol de beneficiar toda a comunidade através de uma política de turismo.

b) planejamento - estabelece as linhas gerais para que o desenvolvimento ocorra de modo ordenado, previamente escolhido e que beneficie o maior número de grupos sociais.

c) legislação e regulamentação - as normas codificadas do direito são um importante instrumento, pois estabelecem regras, limites, impões condições, barram privilégios que são fundamentais para a organização turística.

d) empreendimentos - o estado assume função empresarial podendo ser proprietário e dirigente de empreendimentos turísticos quando a iniciativa privada não assume esse papel.

e) incentivo - caracteriza-se por empréstimos ao setor privado, incentivos fiscais, isenções de taxas, etc.

f) atuação social - apoio do governo ao desenvolvimento do turismo e lazer nas camadas sociais menos favorecidas através do incentivo a construção de colônias de férias por organizações sociais, sindicatos, além de apoiar o turismo social.

g) promoção do turismo - é responsável pela escolha do visitante em visitar determinado país receptor, sendo assim uma importante função das administrações públicas e que tende a aumentar devido a competição globalizada pelo fluxo de turistas e com o reconhecimento do turismo como importante fonte de divisas.

Mediante as sete funções de atuação do governo, é perceptível que o mesmo deva garantir formas de desenvolvimento da atividade turística, proporcionando aos interessados/grupos de interesse a concretização do turismo por meio da gestão pública, de forma a fortalecer o destino com todas as ações acima destacadas.

Deve-se, então, fixar as políticas específicas de turismo, uma vez que apresenta 
repercussões em vários níveis, como o ambiental, o sociocultural e o econômico, que precisam ser avaliadas e controladas permanentemente, sob o risco de esgotamento da própria atividade. A fixação de objetivos fornece a orientação básica para que os setores público e privado conduzam suas ações.

Por outro lado, Lobato (2001, p.91) comenta que:

As sociedades dos núcleos turísticos devem ter as suas participações garantidas quando da elaboração das políticas de turismo, o que permitirá que os benefícios decorrentes de sua implantação possam ser usufruídos tanto pelas comunidades quanto pelos empresários e pelo setor público, garantindo-se assim também a divisão de responsabilidades.

Dessa forma, verifica-se que a atuação do poder público é de suma importância no estabelecimento de políticas eficazes para a atividade, valorizando tanto o setor privado quanto a sociedade, promovendo as localidades e dinamizando as economias dos países, principalmente aqueles em desenvolvimento.

Para equilíbrio das ações do setor público, reforça-se a necessidade do planejamento do turismo baseado na capacidade de sustentação dos lugares turísticos, para que os impactos causados pela atividade contribuam para a qualidade de vida, melhoria da infraestrutura, geração de empregos e elevação de renda, entre outros aspectos (Dias, 2003).

Desde a década de 1990, novas formas de planejamento têm sido buscadas nas várias esferas governamentais (federal, estadual e municipal), articuladas entre si, gerando intensificação da execução das políticas públicas. Além desse aspecto, o desafio se volta à integração da participação dos atores direta e indiretamente participantes da atividade turística.

Vieira (2008, p.82) chama a atenção para o fato de que:

A chamada gestão democrática caracteriza-se pelo incentivo à participação de todos os atores envolvidos no processo. A população local deve fazer parte do processo decisório das questões relativas ao dia-a-dia destas áreas. O desafio é conseguir atingir um projeto coletivo, onde todos, população, empresários e poder público, tenham tido espaço e feito parte do processo decisório. Para atingir tal desafio, é imprescindível a montagem de uma equipe interdisciplinar muito bem coordenada. Além disso, para manter um processo democrático em uma escala possível de ser gerida, é preciso também que as ações sejam descentralizadas. As estruturas devem possuir uma autonomia que garanta a integração e não apenas a junção. 
Tratando-se de planejamento, é fundamental que um plano turístico tenha finalidades que venham de encontro com a realidade local. Segundo Ruschmann (2010, p.9):

A finalidade do planejamento turístico consiste em ordenar as ações do homem sobre o território e ocupa-se em direcionar a construção de equipamentos e facilidades de forma adequada evitando, dessa forma, os efeitos negativos nos recursos, que os destroem ou reduzem sua atratividade.

Cabe salientar que o planejamento está atrelado a fatores internos e externos e que as administrações públicas que apostam no desenvolvimento do turismo no meio urbano devem atentar para a necessidade do planejamento como elemento básico para instalação de infraestrutura, crescimento econômico, proteção aos recursos frágeis (como meio ambiente e atrações culturais e históricas) e atendimento às necessidades dos autóctones e visitantes (Beni, 2006; Butler, 2008, Carvalho, 2000).

\section{CONSIDERAÇÕES FINAIS}

Constatou-se que há uma forte relação entre políticas públicas, turismo e cidades, pois, estes estão entrelaçados quanto a oferta de produtos e serviços de qualidade no meio urbano que sanam necessidades primárias tanto da comunidade, quanto do turista em relação aos itens básicos de infraestrutura. No entanto, permanece a necessidade de compreensão sobre o fenômeno do turismo no meio urbano, por tratar-se de um segmento peculiar, com pouco material publicado acerca da temática, principalmente, sobre a relação com políticas públicas.

As políticas públicas urbanas em sua maioria não contemplam o turismo, de forma direta, mas suas ações interferem na atividade, principalmente, por se tratar de uma urbe, que necessariamente deve ofertar infraestrutura a sociedade, no qual o turista usufrui. Desta forma, é compreensível que as políticas públicas e a gestão do turismo urbano caminham em paralelo de forma a promover o desenvolvimento do destino, mediante a implantação de políticas, planos, programas e projetos.

Por outro lado, torna-se fundamental a produção de referências sobre políticas públicas e suas influências na gestão do turismo em cidades, tanto positiva quanto negativamente. 
Sugere-se a realização de novas pesquisas bibliográficas, documentais e empíricas, principalmente com recortes regionais que abordem esta perspectiva, tendo urbes como objeto de estudo nos mais diversos níveis (federal, estadual e municipal).

Ratifica-se que o referencial teórico apresentado tratou dos principais aspectos centrais do objetivo da pesquisa, fundamentado em autores sobre turismo urbano, políticas públicas, planejamento urbano, território, geografia do turismo, confirmando a relação entre as temáticas.

\section{REFERÊNCIAS}

Aguiar, M. R. \& Dias, R. (2002). Fundamentos do turismo: conceitos, normas e definições. Campinas, SP: Alínea.

Arretche, M. (2010). Federalismo e igualdade territorial: uma contradição em termos? Revista

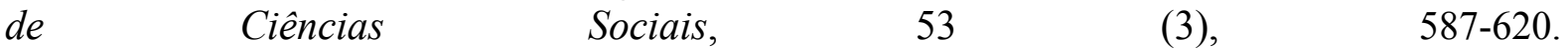

Ashworth, G. \& Page, S. J. (2011). Urban tourism research: recent progress and current paradoxes. Tourism Management. 32 (1),1-15.

Auch, R. Taylor, J., \& Acevedo, W. (2004). Urban growth in American cities. Recuperado em 06 janeiro, 2016, de file: http://pubs.usgs.gov/circ/2004/circ1252/.

Beni, M. C. (2006). Políticas e planejamento de turismo no Brasil. São Paulo: Aleph.

Bonavides, Paulo (2006). Ciência política. São Paulo: Malheiros.

Brasil. (2001). Lei 10257/2001.Recuperada em 10 de novembro, 2015, de http://www.planalto.gov.br/ccivil_03/leis/LEIS_2001/L10257.htm

Butler, R. W. (2008). Tourism: an evolutionary perspective. In: N. J., Gordon, R.W. Butler, \& G.W. Waterloo. (Orgs.).Tourism and sustainable development: monitoring, planning, managing. Ontario: University of Waterloo.

Carvalho, A. F. (2000). Políticas públicas em turismo no Brasil. Sociedade e Cultura, 3 (1-2), 97-109.

Castrogiovanni, A. C. (2013). Turismo, organização e reconstrução do espaço urbano contemporâneo. Revista Rosa dos Ventos, 5 (3), 381-389.

Chang, T. C., Huang, S. (2004). Urban tourism: between the global and the local. In:A.A. Lew, C.M. Hall, \& A.M. Williams,(Orgs.). A companion to tourism. (pp. 223-234). United Kingdom: TJ International.

Cooper, C., Hall, C. M. \& Trigo, L. G. G. (2011). Turismo contemporâneo. Rio de Janeiro: Elsevier. 
Cooper, D. R. \& Schindler, P. S. (2003). Métodos de pesquisa em administração. São Paulo: Bookman.

Dias, R. (2003). Planejamento turístico. São Paulo: Manole.

Exceltur. (2015). El turismo aportó 124.000 a la economía española en 2015. Recuperado em 20 maio, 2016, de file: http:// http://www.hosteltur.com/114522_turismo-aporto-124000-meconomia-espanola-2015.html.

Faria, C. A. P. (2003). Ideias, conhecimento e políticas públicas: um inventário sucinto das principais vertentes analíticas recentes. Revista Brasileira de Ciências Sociais, 18 (51), 21-30.

Gil, A. C. (2006). Como elaborar projetos de pesquisa. São Paulo: Atlas.

Goeldner, C. R., Ritchie, J. R., B \& McIntosh, R. W. (2002). Turismo: princípios, práticas e filosofias. Porto Alegre: Bookman.

González, R. L., P., González, J.M.G. \& Escudero, L.A.. (2012). Los espacios urbanos: el estudio geográfico de la ciudad y la urbanización. Madrid: Biblioteca Nueva.

Hall, C. M. (2011). A review of "Brands and branding geographies and Urban tourism and urban change: cities in a global economy". Journal of Sustainable Tourism. 21 (6), 937-940.

Hayllar, B., Edwards, D., Griffin, T. \& Aldrigui, M. (2011). Turismo em cidades: espaços urbanos, lugares turísticos. Rio de Janeiro: Campus.

Karski, A. (1990). Urban tourism: a key to urban regeneration? The Planner. Royal Town Planning Institute, 76 (13), 15-17.

Knafou, R. (2001). Turismo e território: Para um enfoque científico do turismo. In Rodrigues, Adyr B. Turismo e geografia: reflexões teóricas e enfoques regionais. São Paulo: Hucitec,

Lefebvre, Henri (2011). O direito à cidade. São Paulo: Centauro.

Lobato, F. M. (2001). Descentralização das políticas públicas de turismo: a municipalização do turismo no Maranhão. Dissertação de Mestrado, Universidade de São Paulo, São Paulo, São Paulo, SP, Brasil.

López P. F. (2009). The explosion of urban tourism: the european cities visitors. European Cities Marketing, 25-28

Luchiari, M. T. D. P. (1998). Urbanização turística: um novo nexo entre o lugar e o mundo. In: C. Serrano, H., Bruhns, Turini, \& M.T.D.P. Luchiari. Olhares contemporâneos sobre o turismo. (Cap. 5).Campinas: Papirus. 
Mazaro, R. (2011). Conhecimento científico em ciências sociais e proposição de modelos em turismo. Revista Turismo em Análise. 22 (3),561-578.

Minayo, M. C. S. \& Sanches, O. (1993). Quantitativo-qualitativo: oposição ou complementar idade? Caderno Saúde Pública, 9 (3), 239-248.

Ministério do Turismo [MTur]. (2013). Índice de competitividade do turismo nacional: destinos indutores de desenvolvimento turístico regional. Brasília, DF: Ministério do Turismo.

Mullins, P. (1991). Tourism urbanization. International Journal of Urban and Regional Research, Oxford: Foundation for Urban and Regional Studies; Wiley-Blackwell, 15 (3), 326342.

Nam, T. \& Pardo, T. A. Conceptualizing smart city with dimensions of technology, people, and institutions. The Proceedings of the Annual International Conference on Digital Government Research, 12th

Pearce, D. (2001). Un Esquema Integrador para la investigacion del turismo urbano. Annals of Tourism Research en Espanhol. Universitat de les IIIes Balears. 3 (2), 340- 363.

Pearce, D. (2003). Geografia do turismo: fluxos e regiões no mercado de viagens. São Paulo: Aleph.

Pereira, C. A. S. (1999). Políticas públicas no setor do turismo. Turismo em Análise, 10 (2), 7 21.

Pine, J \& Gilmore, J. (2011). The experience economy. Massachusetts: Harvard Business.

Plaza, G. J. (2006). Territorio, geografía rural y políticas públicas. Desarrollo y sustentabilidad en las áreas rurales. Boletín de la A.G.E., 41, 69-95.

Ritchie, B. W. \& Dickson, T. J. (2006). Assessing the economic impact of built attractions: the case of the Australian Capital Territory. Paper for Cutting Edge Research in Tourism,

Roscoche, L. F. (2013). Turismo no meio urbano e a segregação socioespacial: revisitando problemáticas. Turismo \& Sociedade. 6 (4), 814-834.

Ruiz, T. Domareski, C. \& Gândara, J. M. G. (2013). A relação entre o planejamento urbano e a competitividade dos destinos turísticos. Revista brasileira de Pesquisa em Turismo, 7(2), 260-280.

Rullán, O. (2011). La regulación del crecimiento urbanístico en el litoral mediterráneo español. Ciudad y Territorio. Estudios Territoriales. 43 (168), 279-297.

Ruschmann, D. V. M. (2010). Turismo e planejamento sustentável: a proteção do meio ambiente. Campinas, SP: Papirus. 
Santos, S. R. (2015). Paisagem solidária: indicadores de sustentabilidade urbana em área turística funcional do centro histórico de São Luís, Maranhão. Tese de Doutorado, Pontifícia Universidade Católica do Paraná, Curitiba Paraná, PR, Brasil.

Santos, S. R. (2008). Políticas públicas e suas contribuições para o desenvolvimento turístico do Maranhão. Itinerários, 3, 95-104.

Sanz-Ibáñez, C. \& Anton C. S. (2014). The evolution of destinations: towards an evolutionary and relational economic geography approach. Tourism Geographies. 16 (4),563-579.

Solha, K. (2004). Órgãos públicos estaduais e o desenvolvimento do turismo no Brasil. Dissertação de Mestrado, Universidade de São Paulo, São Paulo, SP, Brasil.

Souza, C. (2004). Governos locais e gestão de políticas sociais universais. São Paulo em Perspectiva, 18(2), 27-41.

Stokes, P. (2012). Os 100 pensadores essenciais da filosofia. São Paulo: Difel.

Theobald, W. F. (2002). Significado, âmbito e dimensão do turismo. In: W.F. Theobald. (Org.). Turismo global. (Cap.1). São Paulo: Editora do Serviço Nacional de Aprendizagem Comercial[ SENAC].

Tyler, D., Guerrier, Y. \& Robertson, M. (Orgs.) (2001). Gestão do turismo municipal: teoria e prática de planejamento turístico nos centros urbanos. São Paulo: Futura.

Vieira, N. M. (2008). Gestão de sítios históricos: a transformação dos valores culturais e econômicos em programas de revitalização em áreas históricas. Recife: Editora da Universidade Federal de Pernambuco [UFPE].

Yázigi, E. (2003). Civilização urbana, planejamento e turismo: discípulos do amanhecer. São Paulo: Contexto.

Yázigi, E. (2009). Saudades do futuro: por uma teoria do planejamento territorial do turismo. São Paulo: Plêiade. 